\title{
Can Trichogramma atopovirilia Oatman \& Platner replaces Trichogramma galloi Zucchi for Diatraea saccharalis (Fabricius) control?
}

\author{
Carolina Tieppo Camarozano ${ }^{1 \oplus}$, Aloísio Coelho Jr. ${ }^{1 *} \odot$, Ranyse Barbosa Querino da Silva ${ }^{2} \odot$, José Roberto Postali Parra ${ }^{\circledR}$
}

'Universidade de São Paulo/ESALQ - Depto. de Entomologia e Acarologia, C.P. 09 - 13418-900 - Piracicaba, SP - Brasil. 2Embrapa Sede, Parque Estação Biológica, s/n - 70770-901 - Brasília, DF - Brasil.

*Corresponding author <aloisiocoelho@usp.br>

Edited by: Paulo Cesar Sentelhas

Received October 15, 2020

Accepted January 15, 2021
ABSTRACT: Studies on aggressiveness of parasitoids, as assessed by their parasitism against pests, used in biological-control programs are highly important to select the most suitable species and/or strain to control insect pests. The present study investigated whether the egg parasitoid Trichogramma galloi Zucchi, an efficient control agent for sugarcane borer Diatraea saccharalis (Fabricius) in Brazil, could be replaced by Trichogramma atopovirilia Oatman \& Platner, a parasitoid easier to mass-produce, since it has been found parasitizing $D$. saccharalis eggs in the warmest region of Brazil and Argentina. Three strains of the genus Trichogramma were compared: T. atopovirilia (ATP strain) reared on a factitious host Anagasta kuehniella (Zeller); T. atopovirilia isoline ATP-I, reared on D. saccharalis eggs for six generations; and T. galloi, reared on A. kuehniella eggs. We measured parasitism of each strain for $72 \mathrm{~h}$ and for the entire life span, parasitism rate per cluster of $D$. saccharalis eggs, number of parasitoids emerged (parasitism viability), and parasitoid life span. The results confirmed that $T$. galloi is the best species for $D$. saccharalis control, showing higher control potential, since parasitism and emergence rate were higher for this species. Although $T$. atopovirilia ATP-I performed reliably in all parameters, T. galloi exceeded and was the most indicated for mass-rearing in control programs for sugarcane borer.

Keywords: biological control, egg parasitoid, strain selection, sugarcane borer

\section{Introduction}

The egg parasitoid Trichogramma galloi Zucchi has been increasingly used in biological control (BC) programs for Diatraea saccharalis (Fabricius) in Brazil. From 2010 to 2018 , the area treated increased $400 \%$ reaching two million ha (Parra, 2010; Parra and Coelho Jr., 2019). Trichogramma galloi is advantageous in controlling $D$. saccharalis because it parasitizes the pest in the egg stage, preventing further damages to the crop. Moreover, $T$. galloi has high specificity in attacking only $D$. saccharalis eggs (Parra and Zucchi, 2004). For these reasons, interest in releasing T. galloi in crops has increased considerably in recent years.

Although $T$. galloi efficiently controls the sugarcane borer in different conditions, rearing this parasitoid in bio-factories is labor-intensive due to the use of factitious hosts. Adapting a population to a factitious host could be a bottleneck for commercial production once $T$. galloi accepts eggs from $A$. kuehniella with at least one week in cold storage (Spínola-Filho et al., 2014); furthermore, it has a parasitism ratio (parasitoid: egg), about 1:4 to 1:6 (Parra et al., 2004). On the other hand, the parasitoid Trichogramma atopovirilia Oatman \& Platner is a more robust species, easy to rear in factitious hosts, it accepts eggs with up to 30 days of storage, and it parasitizes a higher proportion of eggs (1:15) (Coelho Jr., unpublished data).

Trichogramma atopovirilia has been reported parasitizing eggs of $D$. saccharalis in rice fields in the states of Tocantins and Piauí, northern and northeastern Brazil (Silva, 2018, unpublished data), and in the Tucumán province in Argentina (Isas et al., 2016). According to Browning and Melton (1987), parasitism of $T$. atopovirilia in $D$. saccharalis eggs is low compared to T. fuentesi Torre. However, each species of Trichogramma Westwood varies widely between strains. Several authors have reported large differences between Trichogramma strains in biological parameters, especially fertility (Sorati et al., 1996; Thomson and Hoffmann, 2002; Coelho Jr. et al., 2016). According to Parra et al. (2015), a BC program that does not take intraspecific characteristics of Trichogramma into account is likely to fail.

Trichogramma atopovirilia is easier to rear and is reported to occur naturally in $D$. saccharalis eggs, besides the genus Trichogramma shows intraspecific variability, especially in fertility. Therefore, this study compared the efficiency of parasitism in $D$. saccharalis eggs of three strains of Trichogramma: T. atopovirilia reared on a factitious host A. kuehniella; T. atopovirilia isoline ATP-I, reared on D. saccharalis; and T. galloi, reared on A. kuehniella.

\section{Materials and Methods}

\section{Rearing Diatraea saccharalis}

Eggs of Diatraea saccharalis were obtained from a laboratory rearing. Four larvae from these eggs were inoculated into individual flat-bottom glass tubes $(25$ $\mathrm{mm} \varnothing \times 85 \mathrm{~mm} \mathrm{~h}$ ), containing approximately $20 \mathrm{~mL}$ of the artificial diet proposed by Hensley and Hammond (1968). The tubes were kept in a climate-controlled room 
at $25 \pm 2{ }^{\circ} \mathrm{C}, 60 \pm 10 \% \mathrm{RH}$, and 14-h photophase, until the pupa stage. Approximately 25 days after inoculation, pupae of both sexes were transferred to emergence cages of a PVC tube $(10 \mathrm{~cm} \varnothing \times 20 \mathrm{~cm} \mathrm{~h})$ with a Petri dish (15 $\mathrm{cm} \varnothing /$ lined with moistened filter paper on the bottom and a second Petri dish of the same size to cover the cage top. The PVC tube was lined inside with white paper, changed, and moistened daily, where $D$. saccharalis eggs were laid.

The eggs collected were stored in Petri dishes (15 $\mathrm{cm} \varnothing /$ lined with moistened filter paper to keep humidity. Some egg-clusters were used in the experiments $(80 \%)$ and others were used to continue the rearing, kept in the laboratory at $25 \pm 2{ }^{\circ} \mathrm{C}, 60 \pm 10 \% \mathrm{RH}$, and 14 -h photophase.

\section{Rearing Trichogramma strains}

The Trichogramma strains used in the study were kept in a rearing colony in the laboratory. The strains were reared on eggs of Anagasta kuehniella, the most suitable factitious host (Parra et al., 2015). These eggs were also obtained from the rearing colony kept at laboratory, which uses a diet based on $97 \%$ whole-wheat flour and $3 \%$ brewer's yeast, according to the method described by Parra (1997).

The eggs of $A$. kuehniella from the rearing colony were placed on a sheet of white cardboard $(17 \mathrm{~mm} w \times$ $77 \mathrm{~mm} \mathrm{~h}$ ), affixed with double-sided tape, and rendered unviable by exposure to germicidal light for $50 \mathrm{~min}$ (Stein and Parra, 1987). At the egg-card top, the strain code to which the eggs would be offered and the date of parasitism exposure were noted.

Unviable eggs were offered for parasitism to adults of the different Trichogramma strains, in flat-bottom glass tubes $(25 \mathrm{~mm} \varnothing \times 85 \mathrm{~mm} h)$ for $48 \mathrm{~h}$. For food, the adults were provided a droplet of pure honey, deposited at the egg-card top with the No. 00 entomological pin. The tubes were kept in a controlled room at $25 \pm 2{ }^{\circ} \mathrm{C}, 60$ $\pm 10 \% \mathrm{RH}$, and 14-h photophase while the parasitoids developed. After $48 \mathrm{~h}$, the parasitized egg-cards were transferred to new tubes without Trichogramma and approximately 10 days after the eggs were offered for parasitism, parasitoids emerged.

New egg-cards with killed eggs were offered to the adults to continue the rearing.

\section{Trichogramma species and strain selection}

Three strains were selected for the experiment. Trichogramma atopovirilia (ATP strain) and T. galloi reared in eggs of the factitious host $A$. kuehniella were used. The third strain was an isoline termed ATP-I, selected from $T$. atopovirilia (ATP) developed in eggs of $D$. saccharalis for six generations. Taxonomy of the species was confirmed by Dr. Jaci Mendes Vieira, a specialist in Trichogramma.

The T. galloi strain used was originally collected from D. saccharalis eggs in Santa Vitória, Minas Gerais,
Brazil (18 50'20" S, 5007'15" W, altitude $498 \mathrm{~m})$ (tropical climate with dry winters, Köppen $A w$ ) (Kottek et al., 2006). The ATP strain, T. atopovirilia, was collected in the municipality of São José dos Pinhais, Paraná, Brazil (2532'06" S, 49¹2'21" W, altitude $906 \mathrm{~m}$ ) (temperate climate with mild summers, Köppen $C f b$ ) in eggs of corn earworm Helicoverpa zea (Boddie).

For the selection of ATP-I strain, an egg-card containing several egg-clusters of $D$. saccharalis was exposed to parasitism by female of $T$. atopovirilia (ATP) in a 600-mL glass tube. Regarding feed for adults, a droplet of pure honey was deposited on the tube wall with an No. 00 entomological pin. Parasitism was allowed until the insects died. After nine days, egg-clusters containing darkened eggs, indicating parasitism by Trichogramma, were cut from the cardboard and transferred to a new glass tube for emergence and a new set of egg-clusters was exposed to parasitism. This process was repeated for six generations thus genetic variability (nuclear background) for the strain was expected to be low (Li, 1955).

Fifteen selected females were placed individually in flat-bottom glass tubes $(25 \mathrm{~mm} \varnothing \times 85 \mathrm{~mm} \mathrm{~h})$ to create an isoline (isofemale line). Each of the 15 females was offered a $D$. saccharalis egg-cluster and a droplet of pure honey on the tube wall for food. Parasitism was allowed until they died. The most-parasitized egg-cluster was chosen to breed the isoline and an A. kuehniella eggcard was offered for the emerged adults to parasitize.

The most parasitized $D$. saccharalis egg-cluster was chosen to rear the isoline and adults emerged from the egg-card were then reared on $A$. kuehniella egg-cards for two generations in order to prevent pre-imaginal conditioning. Adults of the selected ATP-I strain emerged from the egg-card containing A. kuehniella eggs were used as one of the treatments for the experiment, along with T. atopovirilia (ATP strain) and T. galloi, setting up the three experimental strains.

\section{Trichogramma parasitism efficiency on Diatraea saccharalis eggs}

To conduct the experiment, 30 newly emerged and mated females from each strain were placed in individual flatbottom glass tubes $(25 \mathrm{~mm} \varnothing \times 85 \mathrm{~mm} \mathrm{~h})$. Again, a droplet of pure honey was deposited on the tube wall as food for the adults. The glass tubes were closed with plastic film and kept in a climate-controlled chamber at $25 \pm 1{ }^{\circ} \mathrm{C}, 75 \pm 10 \% \mathrm{RH}$, and 14-h photophase. Eggclusters with about $40 \mathrm{D}$. saccharalis eggs were offered daily to Trichogramma females in the tubes. This process was repeated until all females died in order to assess their life span.

The egg-clusters offered for parasitism were less than $24 \mathrm{~h}$ old. The parasitized egg-clusters were collected daily from the tubes containing the females and placed in a new tube of the same dimensions. The new tubes, containing the presumably parasitized egg- 
clusters, were kept in the same controlled chamber until the end of parasitoid development.

Total parasitism (fertility) was evaluated based on the number of parasitized (darkened) eggs. Parasitism by the $3^{\text {rd }}$ day $(72 \mathrm{~h})$, considered the action time of Trichogramma in the field (Kazmer and Luck, 1995), was also assessed. Parasitism viability (emergence) was obtained based on the proportion between dark eggs and the number of eggs with an exit hole. Non-parasitized eggs were also counted until the $3^{\text {rd }}$ day to obtain the parasitism rate per egg-cluster. Life span was assessed by daily observation of female mortality.

\section{Statistical analysis}

For each Trichogramma strain, 30 females were evaluated using a completely randomized design. The quasiPoisson generalized linear model (GLM) (Demétrio et al., 2014) was applied to the data for total parasitism and parasitism until the $3^{\text {rd }}$ day. For the analysis of parasitism rate and viability (emergence), the quasi-binomial generalized linear model was used. Quality of the model adjustments was verified by fitting half-normal envelope curves (Moral et al., 2017). When differences were found, the Tukey test was used to compare the means with a $95 \%$ reliability index, designed for the GLM analysis using the GLHT package (Hothorn et al., 2008). A survival curve was used to assess life span. All analyses used the statistical software " $\mathrm{R}$ ", version 3.2.2.

\section{Results and Discussion}

Based on the parasitism capacity of the different species and strains over $72 \mathrm{~h}$ (three days), T. galloi was superior, parasitizing $11.68 \pm 0.94$ eggs $\left(\mathrm{F}_{2: 86}=91.63 ; p<0.001\right)$ (Table 1), a much higher number than that found for $T$. atopovirilia strains ATP-I and ATP. Strain ATP-I parasitized more eggs than ATP, indicating that the selection on $D$. saccharalis eggs increased efficiency; however, both strains were inferior to $T$. galloi, parasitizing only $2.63 \pm$ 0.50 and $1.07 \pm 0.25$ eggs, respectively. Total parasitism per female differed significantly $\left(\mathrm{F}_{3 ; 116}=55.84 ; p<0.001\right)$ between the two T. atopovirilia strains and T. galloi. Again, T. galloi (GA) was superior to ATP-I (3.03 eggs) and ATP (2.13 eggs) and, in the latter, two strains did not differ from each other in the total number of parasitized eggs (Table 1). Regarding parasitism rate (72 h) per $D$. saccharalis eggcluster, T. galloi showed higher parasitism than the other strains, with a mean of $9.24 \pm 0.6 \%$ parasitized eggs per egg-cluster, higher than percentages for ATP-I I (1.87 \pm $0.3 \%)$ and ATP $(0.74 \pm 0.2 \%)$, which differed from each other $\left(\mathrm{F}_{2: 87}=86.46, p=0.001\right)$ (Table 1$)$.

Life spans of the three strains showed that, differently from parasitism data, strain ATP-I showed the highest longevity, with a mean of $11.0 \pm 0.55$ days, although without a major difference from strain ATP $(9.1 \pm 0.62)$. Life span of $T$. galloi GA was significantly shorter $(8.5 \pm 0.50$ days $)\left(X_{3}^{2}=11.1 ; p=0.01\right)$ (Table 2$)$.
Regarding parasitism viability, the three strains and species showed no significant differences, ranging from 20.8 to $52.1 \%\left(\mathrm{~F}_{2 ; 43}=2.96, p=0.06\right)$ (Table 2).

All three species and strains parasitized eggs of $D$. saccharalis, which suggests that in nature, if it does not locate its natural host, T. atopovirilia can use eggs of $D$. saccharalis as a host. Each parasitoid species has distinct characteristics; however, there are also intraspecific differences among strains. Several authors have described T. pretiosum strains by showing differences in their biological parameters, such as flight capacity, both in the laboratory and in the field (Cerutti and Bigler, 1995; Coelho Jr. et al., 2018), as well as in parasitism efficiency and dispersal in field conditions (Bourchier and Smith, 1996; Fournier and Boivin, 2000; Coelho Jr. et al., 2016).

In a study conducted in Australia, Trichogramma brassicae Bezdenko showed different reproductive performances in field and laboratory conditions, since strains kept in the laboratory were selected for the artificial environment, losing their potential as BC agents. This characteristic was reconstituted, obtaining isolines, and drastically reduce the genetic variability of these insects (Sorati et al., 1996). According to Coelho Jr. et al. (2016), 45 T. pretiosum isolines showed reproductive performances (parasitism) in the laboratory that clearly differed from one another, similar to other traits, such as spatial distribution, superparasitism, sex ratio, and development rate.

Table 1 - Number of Diatraea saccharalis eggs parasitized by females of Trichogramma spp. for $72 \mathrm{~h}$, total parasitism over the life span, and parasitism rate per egg-cluster of the three Trichogramma strains and species (mean \pm standard error). Temperature $25 \pm 1{ }^{\circ} \mathrm{C}, \mathrm{RH}: 75 \pm 10 \%$ and photophase: $14 \mathrm{~h}$.

\begin{tabular}{lrrr}
\hline Strains & $\begin{array}{c}\text { Parasitized eggs in } \\
72 \mathrm{~h}^{*}\end{array}$ & $\begin{array}{c}\text { Total parasitized } \\
\text { eggs }^{*}\end{array}$ & $\begin{array}{c}\text { Parasitism \% per } \\
\text { egg-cluster }^{*}\end{array}$ \\
\hline ATP-I & $2.63 \pm 0.50 \mathrm{~b}$ & $3.03 \pm 2.89 \mathrm{a}$ & $1.87 \pm 0.33 \mathrm{a}$ \\
ATP & $1.07 \pm 0.25 \mathrm{a}$ & $2.13 \pm 2.27 \mathrm{a}$ & $0.74 \pm 0.17 \mathrm{~b}$ \\
GA & $11.68 \pm 0.94 \mathrm{c}$ & $13.03 \pm 4.98 \mathrm{~b}$ & $9.24 \pm 0.61 \mathrm{c}$ \\
\hline
\end{tabular}

* Means followed by same letter did not differ by the Tukey test $p<0.05$; ATP-I $=T$. atopovirilia isoline, reared on $D$. saccharalis eggs for six generations; $A T P=T$. atopovirilia strain, reared on $A$. kuehniella eggs; $G A=T$. galloi strain, reared on $A$. kuehniella eggs.

Table 2 - Adult life span (in days) and parasitism viability (\%) (mean \pm standard error) on Diatraea saccharalis eggs of the three Trichogramma strains and species. Temperature $25 \pm 1^{\circ} \mathrm{C}, \mathrm{RH}$ : $75 \pm 10 \%$, and photophase: $14 \mathrm{~h}$.

\begin{tabular}{lll}
\hline Strains & Life span (days) & Viability ${ }^{*}$ \\
\hline ATP-I & $11.0 \pm 0.55 \mathrm{a}$ & $28 \pm 16.5 \mathrm{a}$ \\
ATP & $9.1 \pm 0.62 \mathrm{ab}$ & $20.8 \pm 11 \mathrm{a}$ \\
GA & $8.5 \pm 0.50 \mathrm{~b}$ & $52.1 \pm 6.8 \mathrm{a}$ \\
\hline${ }^{*}$ Means followed by same letter did not differ by the Tukey test, $p<0.05 ;$ ATP-I \\
$=T$. atopovirilia isoline, reared on $D$. saccharalis eggs for six generations; ATP \\
$=T$. atopovirilia strain, reared on A. kuehniella eggs; GA = T. galloi strain, \\
reared on A. kuehniella eggs.
\end{tabular}


The unique characteristics of different Trichogramma strains are evident, considering that the same species may have different strains with very particular and divergent inherent characteristics. This suggests that another strain could perhaps accomplish a higher parasitism rate of $D$. saccharalis eggs by $T$. atopovirilia, more adapted to the target host $(D$. saccharalis). In the present study, after the first three days of parasitism, differences were apparent between the isolines selected in D. saccharalis eggs (ATP-I) and the non-selected strain. This finding suggested that the results could be different if the T. atopovirilia strain assessed was the same collected in Brazil (states of Tocantins and Piauí) or Argentina, where it naturally parasitized D. saccharalis (Silva et al., 2018 unpublished data; Isas et al., 2016) rather than the strain kept at labotratory condition, which was originally collected in the state of Paraná (Brazil) parasitizing H. zea eggs. Alternatively, if the initial population of $T$. atopovirilia had higher genetic variability, although kept in laboratory for a few generations, the possibility of finding a more aggressive haplotype toward $D$. saccharalis is greater. Comparing different species, Fournier and Boivin (2000) found that the flight activity of a $T$. pretiosum strain from Canada was higher than a strain of Trichogramma evanescens Westwood introduced from Egypt, because the Egyptian strain was already adapted to the climatic conditions in Canada where the study was conducted. The specific differences that lead to biological differences, according to the authors, are due to evolutionary pressures.

The rearing of $T$. atopovirilia is easier compared to T. galloi for BC programs. The first one adapts better to laboratory conditions and it naturally parasitizes eggs of $D$. saccharalis in rice-fields in Brazil and sugarcane in Argentina. In addition, $T$. atopovirilia shows characteristics of accepting eggs from a factitious host with a longer storage time (Spínola-Filho et al., 2014). All these points motivated this comparative study of the two species, using different strains, which confirmed the superiority of $T$. galloi in parasitizing $D$. saccharalis.

The data from this study indicate that the Paraná strain of T. atopovirilia collected on $H$. zea eggs is not a good candidate to replace $T$. galloi for mass rearing of $D$. saccharalis in BC programs. New experiments should be conducted, using different strains of T. atopovirilia, particularly strains collected in the field parasitizing D. saccharalis eggs. The species of Trichogramma show wide intraspecific variations; therefore, strains of $T$. atopovirilia that naturally parasitize this pest should have a closer parasitoid-host relationship, due to the natural processes of strain selection.

\section{Authors' Contributions}

Conceptualization: Camarozano, C.T.; Coelho Jr., A.; Silva, R.B.Q.; Parra, J.R.P. Data acquisition: Camarozano, C.T.; Coelho Jr., A. Data analysis: Camarozano, C.T.; Coelho Jr., A. Design of methodology: Camarozano, C.T.; Coelho Jr., A.; Parra, J.R.P. Writing and editing: Camarozano, C.T.; Coelho Jr., A.; Silva, R.B.Q.; Parra, J.R.P.

\section{Acknowledgments}

The authors thank Neide Graciano Zério for her aid in the study. We also express gratitude to Janet Reid, JWR Associates, for revising and improving the English version of this article. We thank São Paulo Research Foundation (FAPESP) (Process 2018/02317-5) as part of the São Paulo Advanced Research Center for Biological Control (SPARCBIO) hosted at the Luiz de Queiroz College of Agriculture (ESALQ) of the University of São Paulo (USP), sponsored by FAPESP, Koppert and USP; and the National Institute of Science and Technology Semiochemicals in Agriculture (INCT) (FAPESP $2014 / 50871-0 / C N P q 465511 / 2014-7)$, by the financial support.

\section{References}

Bourchier, R.S.L.; Smith, S.M. 1996. Influence of environmental conditions and parasitoid quality on field performance of Trichogramma minutum. Entomologia Experimentalis et Applicata 80: 461-468.

Browning, H.W.; Melton, C.W. 1987. Indigenous and exotic Trichogrammatids (Hymenoptera:Trichogrammatidae) evaluated for biological control of Eoreuma loftini and Diatraea saccharalis (Lepidoptera:Pyralidae) borers on sugarcane. Environmental Entomology 16: 360-364.

Cerutti, F.; Bigler, F. 1995. Quality assessment of Trichogramma brassicae in the laboratory. Entomologia Experimentalis et Applicata 75: 19-26.

Coelho Jr., A.; Rugman-Jones, P.F.; Reigada, C.; Stouthamer, R.; Parra, J.R.P. 2016. Laboratory performance predicts the success of field releases in inbred lines of the egg parasitoid Trichogramma pretiosum (Hymenoptera:Trichogrammatidae). PLoS One 11: e0146153.

Coelho Jr., A.; Stouthamer, R.; Parra, J.R.P. 2018. Flight propensity of isofemale lines of Trichogramma pretiosum Riley in two relative humidity levels. Florida Entomologist 101: 364-368.

Demétrio, C.G.B.; Hinde, J.; Moral, R.A. 2014. Models for overdispersed data in entomology. p. 219-259. In: Ferreira, C.P.; Godoy, W.A.C., eds. Ecological modelling applied to entomology. Springer, New York, NY, USA.

Fournier, F.; Boivin, G. 2000. Comparative dispersal of Trichogramma evanescens and Trichogramma pretiosum (Hymenoptera:Trichogrammatidae) in relation to environmental conditions. Environmental Entomology 29: 55-63.

Hensley, S.D.; Hammond, A.H. 1968. Laboratory techniques for rearing the sugar cane borer on an artificial diet. Journal of Economic Entomology 61: 1742-1743.

Hothorn, T.; Bretz, F.; Westfall, P. 2008. Simultaneous inference in general parametric models. Biometrical Journal 50: 346363. 
Isas, M.; Albarracin, E.L.; Pérez, M.L.D.P.; Salvatore, A. 2016. Trichogramma (Hymenoptera: Trichogrammatidae) species, egg parasitoids of Diatraea saccharalis (Lepidoptera: Crambidae) on sugarcane (Poales: Poaceae) in Argentina. Florida Entomologist 99: 133-134.

Kazmer, D.J.; Luck, R.F. 1995. Field tests of the size fitness hypothesis in the egg parasitoid Trichogramma pretiosum. Ecology 76: 412-425.

Kottek, M.; Grieser, J.; Beck, C.; Rudolf, B.; Rubel, F. 2016. World map of the Köppen-Geiger climate classification updated. Meteorologische Zeitschrift 15: 259-263.

Li, C.C. 1955. Population genetics. University of Chicago Press, Chicago, IL, USA.

Moral, R.A.; Hinde, J.; Demétrio, C.G.B. 2017. Half-normal plots and overdispersed models in R: the hnp package. Journal of Statistical Software 81: 1-23.

Parra, J.R.P.; Coelho Jr., A. 2019. Applied biological control in Brazil: from laboratory assays to field application. Journal of Insect Science 19: 1-6.

Parra, J.R.P. 2010. Mass rearing of egg parasitoids for biological control programs. p. 267-292. In: Cônsoli, F.; Parra, J.R.P.; Zucchi, R.A., eds. Egg parasitoids in agroecosystems with emphasis on Trichogramma. Springer, New York, NY, USA.

Parra, J.R.P. 1997. Rearing techniques of Anagasta kuehniella, factitious host for Trichogramma production = Técnicas de criação de Anagasta kuehniella, hospedeiro alternativo para produção de Trichogramma. p. 121-150. In: Parra, J.R.P.; Zucchi, R.A., eds. Trichogramma and applied biological control = Trichogramma e o controle biológico aplicado. FEALQ, Piracicaba, SP, Brazil (in Portuguese).
Parra, J.R.P.; Zucchi, R.A.; Coelho Jr., A.; Geremias, L.D.; Cônsoli, F.L. 2015. Trichogramma as a tool for IPM in Brazil. p. 472-496. In: Vinson, B.; Greenberg, S.M.; Liu, T.; Rao, A.; Volosciuk, L.F., eds. Augmentative biological control using Trichogramma spp.: current status and perspectives. Northwest A\&F University Press, Shaanxi, China.

Parra, J.R.P.; Zucchi, R.A. 2004. Trichogramma in Brazil: feasibility of use after twenty years of research. Neotropical Entomology 33: 271-281.

Sorati, M.; Newman, M.; Hoffmann, A.A. 1996. Inbreeding and incompatibility in Trichogramma nr. brassicae: evidence and implications for quality control. Entomologia Experimentalis et Applicata 78: 283-290.

Spínola-Filho, P.R.C.; Leite, G.L.D.; Soares, M.A.; Alvarenga, A.C.; Paulo, P.D.; Tuffi-Santos, L. 2014. Effects of duration of cold storage of host eggs and percent parasitism and adult emergence of each of ten Trichogrammatidae (Hymenoptera) species. Florida Entomologist 97: 14-21.

Stein, C.P.; Parra, J.R.P. 1987. Use of ultraviolet radiation to unviable Anagasta kuehniella (Zeller, 1879) eggs aiming studies with Trichogramma $=$ Uso da radiação ultravioleta para inviabilizar ovos de Anagasta kuehniella (Zeller, 1879) visando estudos com Trichogramma spp. Anais da Sociedade Entomológica do Brasil 16: 229-233 (in Portuguese).

Thomson, L.J.; Hoffmann, A.A. 2002. Laboratory fecundity as predictor of field success in Trichogramma carverae (Hymenopt era:Trichogrammatidae). Journal of Economic Entomology 95: 912-917. 